\title{
The Impact of Tropospheric Anomalies on Sea-Based JPALS Integrity
}

\author{
Yue Zhang and Zhipeng Wang * \\ School of Electronic Information Engineering, Beihang University, Beijing 100191, China; \\ zhangyue9405@buaa.edu.cn \\ * Correspondence: wangzhipeng@buaa.edu.cn; Tel.: +86-10-8233-6977
}

Received: 10 June 2018; Accepted: 1 August 2018; Published: 7 August 2018

\begin{abstract}
The Joint Precision Approach Landing System (JPALS) addresses tropospheric errors through double-difference and tropospheric model correction. Large residuals occur with two types of tropospheric anomalies: the vertical duct and horizontal non-nominal troposphere. Through analyzing 8 years of meteorological data from the European Center for Medium-Range Weather Forecasts (ECMWF), we find that the two types of anomalies can occur simultaneously. In addition, the existing vertical protection level (VPL) calculation method under tropospheric anomalies is based on the least squares method, which is not applicable to Sea-Based JPALS using the Kalman filter. Therefore, we start by calculating the zenith duct error by numerical integration. The maximum error observed is $45.64 \mathrm{~mm}$, and the error seasonal characteristic is analyzed. For the non-nominal troposphere, the worst meteorological conditions in the Chinese surrounding sea areas are used to calculate the non-nominal errors, which are fitted to a satellite-elevation-dependent model. Then, a VPL calculation method based on the Kalman filter under tropospheric anomalies is proposed. Finally, a multiple approach simulation is conducted. The results show that the average VPL increments introduced by the duct and non-nominal troposphere anomalies are $0.082 \mathrm{~m}$ and $0.211 \mathrm{~m}$, respectively, with growth percentages of $12.903 \%$ and $30.857 \%$, respectively. The increment under simultaneous anomalies is $0.272 \mathrm{~m}$ with a growth of $40.427 \%$. Furthermore, the average availability under normal conditions is $100 \%$. Considering the duct and the non-nominal troposphere anomalies, the availability loss is $0.017 \%$ and $3.674 \%$, respectively. Under simultaneous anomalies, this loss is $4.743 \%$.
\end{abstract}

Keywords: Sea-Based JPALS; troposphere delay; tropospheric duct anomaly; non-nominal troposphere; VPL

\section{Introduction}

The troposphere is the lower part of the atmosphere over the earth's surface, extending from the surface to a height of approximately $16 \mathrm{~km}$. Tropospheric refraction causes delays in satellite signal transmission. The amount of tropospheric delay in the zenith direction is approximately $2.3 \mathrm{~m}$, which results in a slant delay of approximately $23.5 \mathrm{~m}$ for a satellite with an elevation of $5^{\circ}$ [1].

Unlike the ionosphere, the troposphere is a non-dispersive medium at Global Navigation Satellite System (GNSS) carrier frequencies. That is, the tropospheric impacts on GNSS signal transmission are independent of the working frequency and thus cannot be eliminated using dual or multiple frequency technology [2]. Therefore, the tropospheric delay is an important error source in precise GNSS applications.

Under normal conditions, the majority of the tropospheric delay can be removed by a tropospheric model. Several models exist that describe the nominal tropospheric delay under nominal conditions, including the Hopfield, Modified Hopfield, and Saastamoinen models [2,3]. In differential 
augmentation systems, such as the Ground Based Augmentation System (GBAS) and Joint Precision Approach Landing System (JPALS), under normal conditions, the meteorological conditions at the airport and ship are similar, and the tropospheric delay can be nearly eliminated by differential processing. However, under severe weather conditions such as heavy rainfall, tropospheric anomalies may occur, and the tropospheric errors cannot be completely eliminated by this method, resulting in differential residual tropospheric errors. The residual errors adversely affect the system accuracy and integrity performance [4]. Recent observations showing unexpected atmospheric behavior were reported at the 2014 International Civil Aviation Organization Navigation System Panel meeting and subsequently confirmed by the Federal Aviation Administration (FAA) and Boeing. The observations showed that significant spatial gradients with no link to ionosphere activity could be related to a non-modelled behavior of the troposphere $[5,6]$.

Most of the previous studies in this context were conducted on GBAS, and there are few results on the impacts of tropospheric anomalies on the integrity of Sea-Based JPALS. JPALS is a GNSS-based military all-weather high-accuracy precision approach and landing system developed by the United States; it encompasses Land-Based JPALS and Sea-Based JPALS [7,8]. For aircraft landing, Sea-Based JPALS must provide higher accuracy and integrity performance than land-based applications due to the mobility of the reference station. Due to the highly stringent requirements, Sea-Based JPALS is generally based on carrier-phase differential positioning and Kalman filtering [9], so the corresponding protection level calculation method under the tropospheric anomaly hypothesis is different from that of GBAS.

As shown in Figure 1, three tropospheric delay components are critical to Sea-Based JPALS. The total tropospheric delay observed at the ship station is composed of the delay over paths 1 and 2 (defined by the aircraft height). However, the aircraft, being at a higher height, is subject only to a delay over path 3 . Under nominal conditions, the delays over paths 2 and 3 are highly spatially correlated and can be almost eliminated by differential processing. For the delay over path 1 , a simple empirically derived model is used for this tropospheric correction (TC) [10]. There are then two types of tropospheric anomalies that affect JPALS. First, the large difference between the actual tropospheric delay on path 1 and the TC model value causes the tropospheric duct anomaly error [11]. Second, the arge horizontal troposphere gradient causes significantly different delays over paths 2 and 3, which is called the non-nominal troposphere.

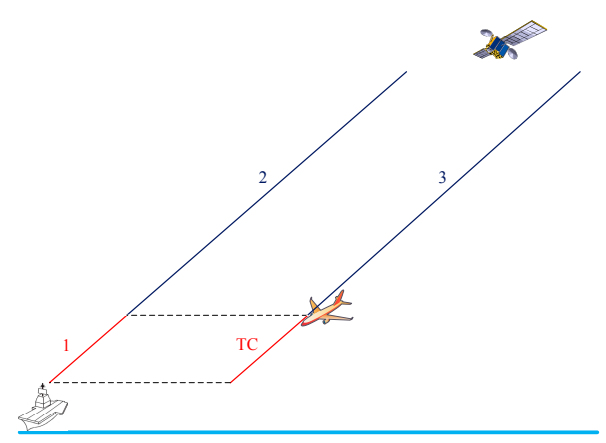

Figure 1. Tropospheric delay paths.

In 2011, a three-parameter wedge model for estimating the duct anomaly error and three vertical protection level (VPL) calculation methods for considering the duct anomaly were proposed [11]. In 2015, Ecole National Aviation Civile proposed a protection level calculation method for the non-nominal tropospheric error for GBAS [10]. In 2017, a satellite selection method to reduce the impact of the non-nominal tropospheric error on the GBAS integrity was proposed [12].

The three-parameter wedge model assumes that once the duct ends, the refractivity index instantaneously recovers the nominal profile values, which may not be realistic. Moreover, the protection level calculation methods under tropospheric anomaly hypothesis proposed 
previously are based on the least squares method, which are not applicable to Sea-Based JPALS using Kalman filtering $[13,14]$. In addition, based on 8 years of data covering China and its surrounding areas obtained from the European Center for Medium-Range Weather Forecasts (ECMWF), we found that the two types of tropospheric anomalies can occur simultaneously. However, previous studies have not considered the impact of the simultaneous occurrence of both types of anomalies on JPALS.

Therefore, we first calculate the zenith tropospheric delay (ZTD) error caused by the duct anomaly based on the meteorological data by numerical integration. Second, for the non-nominal troposphere, the worst meteorological conditions in the surrounding sea areas of China are used to calculate the non-nominal errors. Third, a protection level calculation method based on Kalman filtering under tropospheric anomalies is proposed. Finally, a simulation of multiple landing approaches is conducted to analyze the impacts of individual and simultaneous occurrences of the duct and non-nominal troposphere anomalies on Sea-Based JPALS integrity.

\section{Tropospheric Anomalies}

The main causes of tropospheric duct anomaly are temperature inversion, evaporation ducts, air subsidence, and air advection. An evaporation duct typically occurs over large expanses of water, such as the Great Lakes. Air advection typically occurs over coastal regions [11]. For the non-nominal troposphere, the main causes are weather fronts and heavy rainfall. The two anomalies can occur at the same time.

\subsection{Tropospheric Duct Anomaly}

Under nominal tropospheric conditions, the pressure drops exponentially with height, and the temperature decreases with height at an approximate rate of $1 \mathrm{~K} / 100 \mathrm{~m}$ (over the first few kilometers above sea level). As a result, the refractivity gradient over height is approximately $-40 / \mathrm{km}$ [11]. The tropospheric delay on path 1 in Figure 1 can be accurately estimated using the TC model. However, under anomalous atmospheric conditions, tropospheric ducts can be generated that result in a large difference between the actual tropospheric delay on path 1 and the TC value, thus introducing residual TC errors.

Figure 2 shows the three-parameter wedge model for the duct anomaly proposed by the Illinois Institute of Technology. The blue and red lines are the refractive index under normal conditions and the duct anomaly, respectively. The area between the blue and red lines is the estimated zenith error caused by the duct anomaly. The model assumes that once the duct ends, the refractivity index instantaneously recovers the nominal profile values, which may not be realistic. Therefore, we just use the duct gradient to determine whether the duct anomaly exists. The error caused by the duct anomaly is calculated using a numerical integration method.

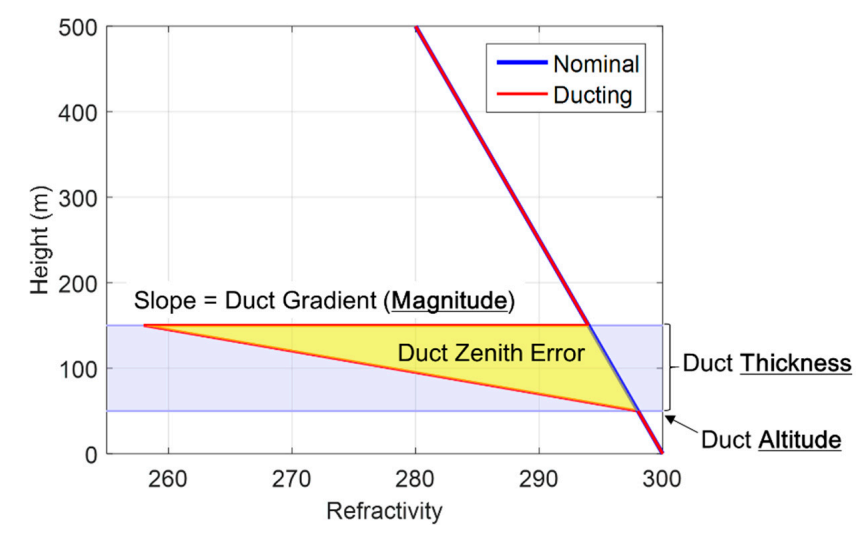

Figure 2. Three-parameter wedge model for duct anomaly [11]. 


\subsection{Non-Nominal Troposphere}

In 2008, Ohio University proposed a "Weather Wall model" for the non-nominal troposphere, as shown in Figure 3 [4]. In this model, the troposphere is partitioned by an infinite vertical plane, either side of which is defined as nominal ' 0 ' and worst-case ' $w$ ' weather conditions for the temperature (T), pressure (P), and relative humidity (RH). In Figure 3, paths 2 and 3 are split into $2 a, 2 b$ and $3 a, 3 b$, respectively. The split is made as the ship station signal leaves the worst-case weather wall. Path 3 is thus contained entirely within the weather wall with conditions $\left(\mathrm{T}_{\mathrm{w}}, \mathrm{P}_{\mathrm{w}}, \mathrm{RH}_{\mathrm{w}}\right)$, while path 2 to the ship experiences nominal conditions $\left(\mathrm{T}_{0}, \mathrm{P}_{0}, \mathrm{RH}_{0}\right)$ during part $2 \mathrm{a}$ and during part $2 \mathrm{~b}\left(\mathrm{~T}_{\mathrm{w}}, \mathrm{P}_{\mathrm{w}}, \mathrm{RH}_{\mathrm{w}}\right)$. The troposphere delay difference experienced by paths $2 \mathrm{a}$ and $3 \mathrm{a}$ is the non-nominal troposphere error. Without loss of generality, the weather wall can be on the right side of the aircraft or on the left side [6].

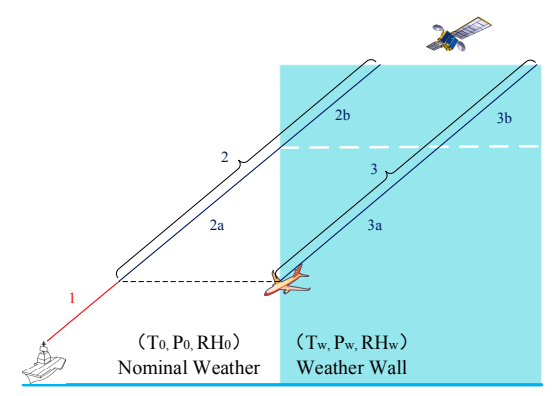

Figure 3. Weather Wall model to the right of the ship.

\section{Tropospheric Error Estimation Based on ECMWF Data}

Studies have shown that the ZTD derived from the ECMWF meteorological data by numerical integration has high precision [15]. Therefore, to study the above mentioned two types of tropospheric anomalies in China and the surrounding areas, the latest 8-year ECMWF ERA5 meteorological data from January 2010 to December 2017 are used.

The time resolution of the data is $1 \mathrm{~h}$, i.e., the data correspond to $0,1,2, \ldots, 23$ UTC. The data have a horizontal resolution of $0.3^{\circ} \times 0.3^{\circ}$ and a vertical resolution of 137 levels reaching $0.1 \mathrm{mbar}$ at the top level. The latitude range of the data is from $3.5^{\circ} \mathrm{N}$ to $54^{\circ} \mathrm{N}$, and the longitude range is from $73^{\circ} \mathrm{E}$ to $135.5^{\circ} \mathrm{E}$.

In the aircraft landing application, tight integrity and accuracy requirements are only required close to the runway and at low altitudes (for example, a $500 \mathrm{~m}$ altitude) [16]. For Sea-Based JPALS, when the distance between the aircraft and ship decreases to $10 \mathrm{~nm}$ (the altitude of the aircraft is approximately $500 \mathrm{~m}$ ), the aircraft enters the final approach area, where the aircraft would start receiving precision data for landing and precision relative navigation is needed. Also, stringent integrity and accuracy requirements are required [14,17]. If a duct exists at an altitude higher than the aircraft altitude $(500 \mathrm{~m})$, it will be eliminated in the differential process. Only ducts that are lower than the aircraft altitude will cause modeling errors that might jeopardize the integrity. Therefore, in this paper, only ducts occurring below $500 \mathrm{~m}$ are considered.

\subsection{Tropospheric Duct Anomaly}

In this paper, the duct gradient is used to determine whether a duct occurs. That is, if the absolute value of the gradient of the refractivity index changes with altitude exceeds $100 / \mathrm{km}$, then the duct anomaly is considered [11]. Figure 4 shows the map of the duct likelihood of occurrence using 8 years of ECMWF data (2010-2017). In this map, only ducts occurring below $500 \mathrm{~m}$ are considered. The map illustrates that the likelihood of a duct appearing below $500 \mathrm{~m}$ in some regions can reach $70 \%$, and in the Bohai Sea it can reach approximately $45 \%$. Therefore, to ensure the integrity of the system, the impact of troposphere ducts must be considered. 


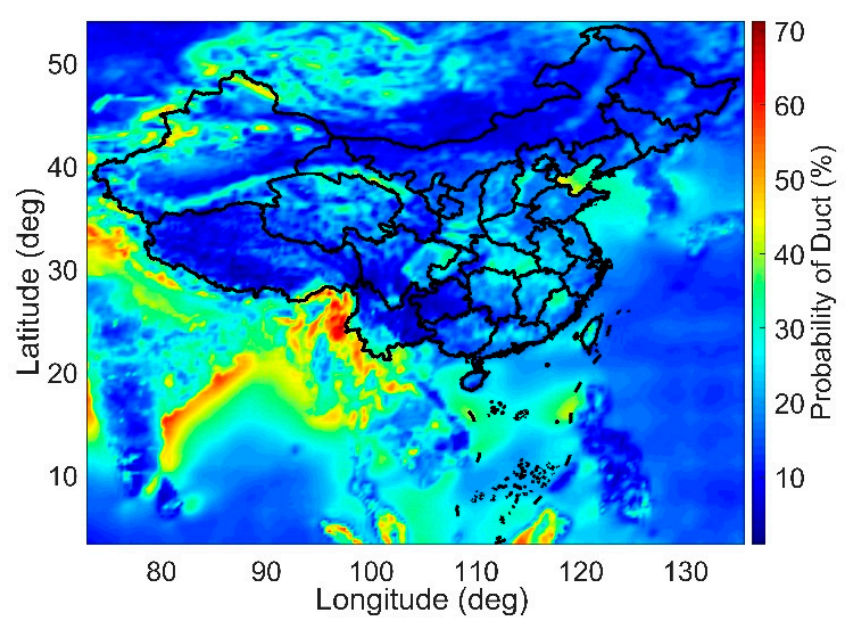

Figure 4. Map of the ducts' likelihood of occurrence.

\subsubsection{Error Estimation Method}

In the TC model, the refractivity $N_{\text {model }}$ is expressed in terms of the reference refractivity $N_{R}$, scale height $h_{0}$ (unit: $\mathrm{m}$ ) and antenna height $z$ (unit: $\mathrm{m}$ ) as follows:

$$
N_{\text {model }}=N_{R} \exp \left(-z / h_{0}\right)
$$

The model zenith tropospheric delay $Z T D_{\text {model }}$ on path 1 is then evaluated by integrating $N_{\text {model }}$ in Equation (1) from the height of the ship to that of the aircraft, which results in

$$
Z T D_{\text {model }}=10^{-6} N_{R} h_{0}\left(1-e^{-\Delta h / h_{0}}\right)
$$

where $\Delta h$ is the height difference between the aircraft and ship (unit: $\mathrm{m}$ ).

Then, the TC model is obtained by mapping the ZTD to the slant domain [18]:

$$
T C=N_{R} h_{0} \frac{10^{-6}}{\sqrt{0.002+\sin ^{2}(\theta)}}\left(1-e^{-\Delta h / h_{0}}\right)
$$

where $\theta$ is the satellite elevation (unit: $\mathrm{rad}$ ).

The standard deviation $\sigma_{\text {tropo }}$ of TC is as follows:

$$
\sigma_{\text {tropo }}=\sigma_{N} \cdot T C / N_{R}
$$

where $\sigma_{N}$ is the standard deviation of refractivity $N$.

The ship is assumed to be at the lowest level, and thus the temperature, pressure, and specific humidity (SH) of the lowest level are used to calculate $Z T D_{\text {model }}$ in Equation (2).

Different from $N_{\text {model }}$, the real refractivity index $N_{\text {real }}$ is calculated using the temperature, pressure, and specific humidity [3]. The real zenith tropospheric delay $Z T D_{\text {real }}$ on path 1 is calculated with ECMWF meteorological data using numerical integration.

$$
Z T D_{\text {real }}=10^{-6} \sum_{i=0}^{M} N_{\text {real }, i} d_{i}
$$

where $N_{\text {real, } i}$ is the real refractivity index at the $i$ th level and calculated with the Ti, Pi, and SH $i$ at that level. $d$ is the height between levels. $M$ is the number of levels below the aircraft altitude. The zenith duct error on path 1 is the difference between $Z T D_{\text {real }}$ and $Z T D_{\text {model }}$. 
Figure 5 shows an example of a duct anomaly. Figure 5 a compares $N_{\text {real }}$ (blue curve) and $N_{\text {model }}$ (red curve) at a selected location $\left(37.8^{\circ} \mathrm{N}, 120.6^{\circ} \mathrm{E}\right)$ in the presence of a duct at 12:00 on 1 June 2017. The refractivity gradient in the presence of a duct is much higher than the nominal case. Figure $5 \mathrm{~b}$ shows $Z T D_{\text {real }}$ and $Z T D_{\text {model, }}$ and Figure 5c shows the zenith duct error for this example. In Figure 5, the zenith duct error at $500 \mathrm{~m}$ is approximately $15 \mathrm{~mm}$, which results in a slant error of approximately $11.49 \mathrm{~cm}$ for a satellite with an elevation of $7.5^{\circ}$. The duct error is much larger than the magnitude of the carrier-phase measurement noise. Therefore, the duct error is an important error source for Sea-Based JPALS.

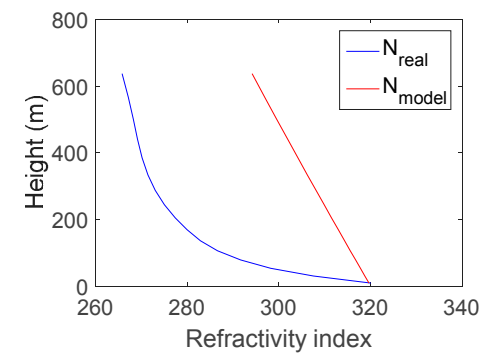

(a)

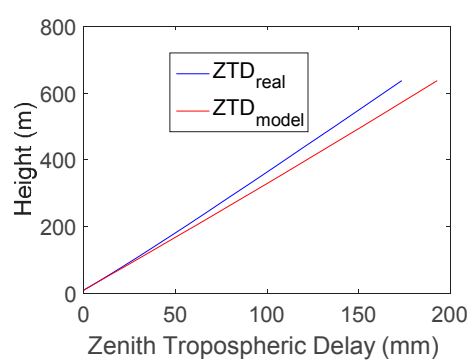

(b)

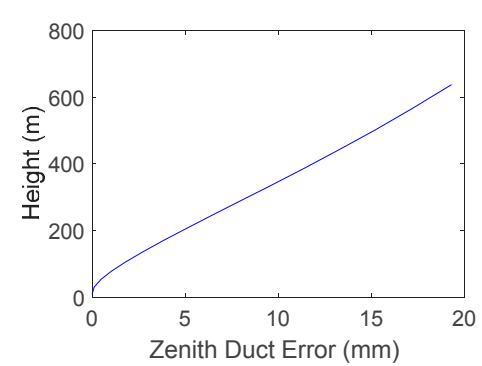

(c)

Figure 5. Example of a duct anomaly at location $\left(37.8^{\circ} \mathrm{N}, 120.6^{\circ} \mathrm{E}\right)$ and time 12:00 on 1 June 2017. (a) shows $N_{\text {real }}$ (blue curve) and $N_{\text {model }}$ (red curve); (b) shows $Z T D_{\text {real }}$ and $Z T D_{\text {model }}$; and (c) shows the zenith duct error for this example.

\subsubsection{Results}

Figure 6 shows the map of the worst-case zenith duct error observed at each grid point in China and the surrounding areas during the period from 2010 to 2017. The large duct errors are mostly found at the junctions of land and water, such as the Balkhash Lake in Southeast Kazakhstan (upper left in Figure 6), the Bay of Bengal, the Andaman Bay (lower left in Figure 6), the Yellow Sea and the Bohai Sea (top right in Figure 6).

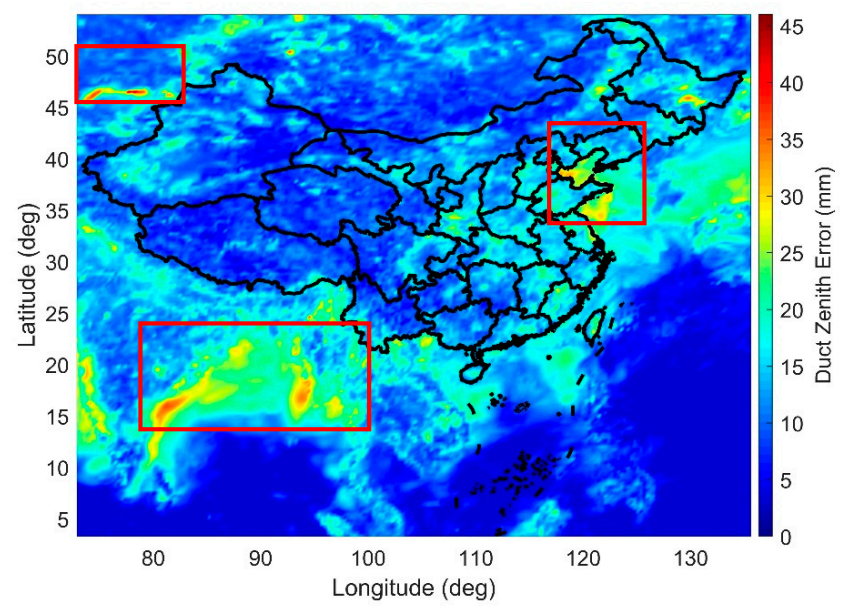

Figure 6. Map of the maximum zenith duct error at $500 \mathrm{~m}$ in China and the surrounding areas (2010-2017).

To provide a better stochastic representation of the data, a histogram of the zenith duct error is shown in Figure 7. This histogram shows that the maximum error range that was observed at $500 \mathrm{~m}$ is $46 \mathrm{~mm}$ at the zenith (approximately $35.24 \mathrm{~cm}$ for a $7.5^{\circ}$ elevation satellite). 


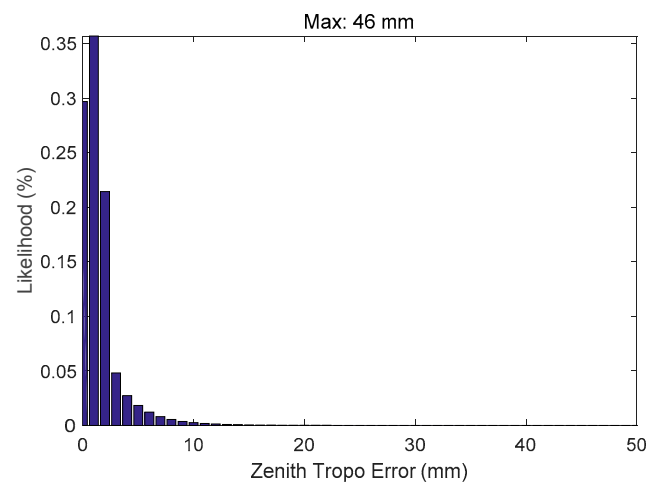

Figure 7. Histogram of the zenith duct error observed at $500 \mathrm{~m}$.

The troposphere has prominent seasonal characteristics [15,19]. Therefore, we separately estimate the maximum duct errors in the four seasons of spring, summer, fall, and winter. The four seasons are divided by the spring equinox (21 March), summer solstice (22 June), fall equinox (23 September), and winter solstice (21 December).

Figure 8 shows maps of the maximum zenith duct errors at $500 \mathrm{~m}$ for the four seasons. Different seasonal features appear for the duct anomaly in different places. In the Bay of Bengal and Andaman Bay, there are larger duct errors in the spring and winter than in the summer and fall. In Balkhash Lake, large duct errors occur in the summer and fall. In the Bohai Sea and Yellow Sea, large duct errors occur in the summer and fall, respectively. For the illustrated area, the maximum zenith duct errors in the four seasons of spring, summer, fall, and winter are $38.46 \mathrm{~mm}, 45.64 \mathrm{~mm}$, $39.98 \mathrm{~mm}$, and $32.98 \mathrm{~mm}$, respectively.

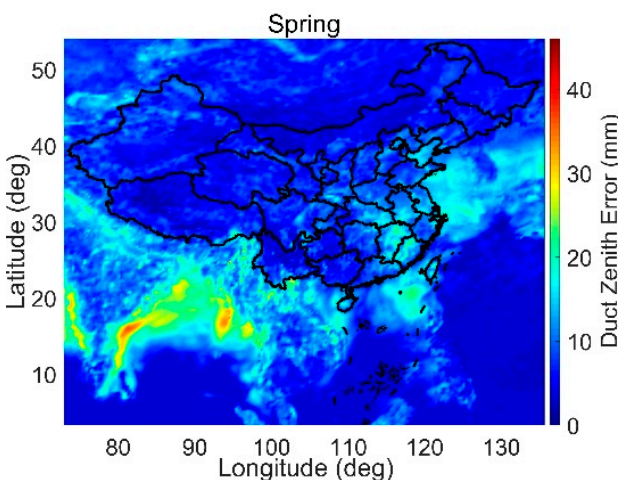

(a)

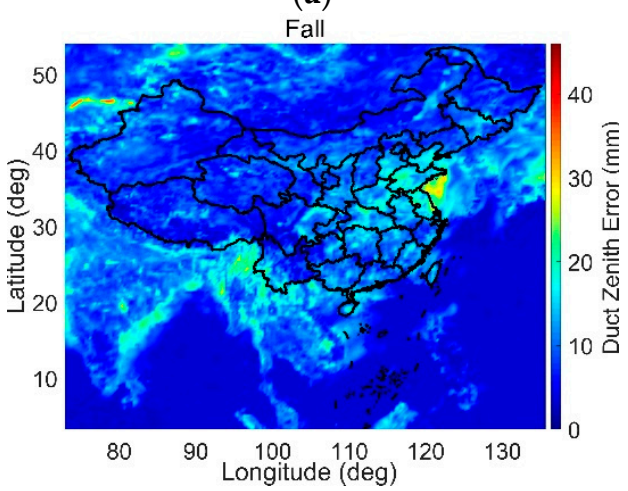

(c)

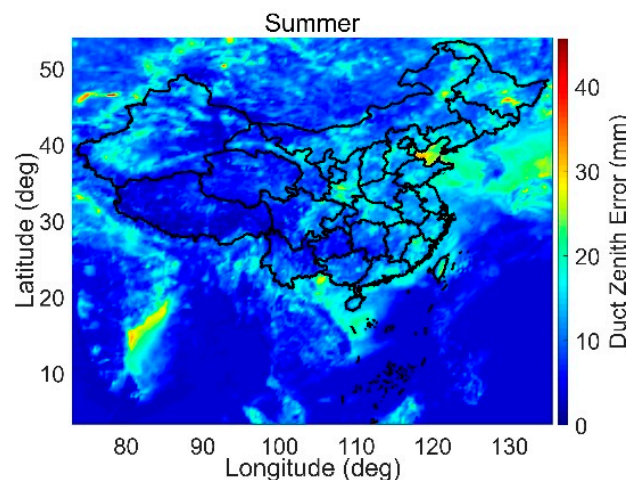

(b)

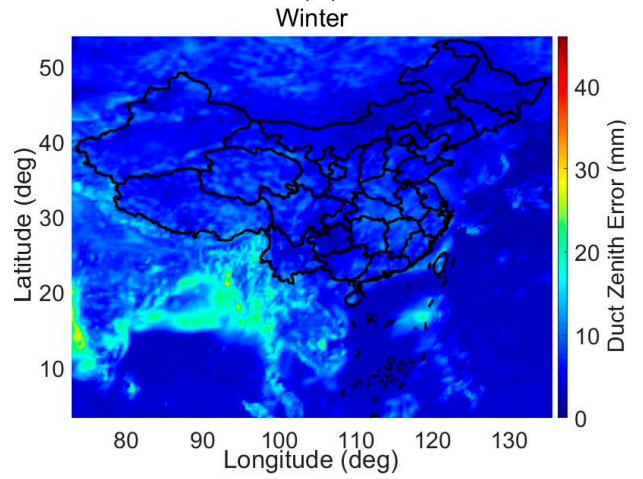

(d)

Figure 8. Maps of maximum zenith duct errors at $500 \mathrm{~m}$ for the four seasons. (a-d) show maps for the spring, summer, fall, and winter, respectively. 
The simulation below is conducted at a location $\left(120.3^{\circ} \mathrm{E}, 39.9^{\circ} \mathrm{N}\right)$ in the Bohai Sea. Figure 9 shows the zenith tropospheric duct errors at the simulated location from 2010 to 2017 . The seasonal variation pattern of the duct errors is prominent and similar every year, and the errors in the summer are generally larger than those in the other three seasons.

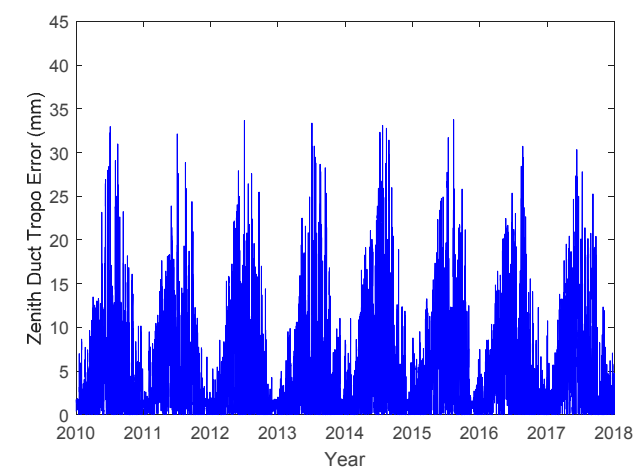

Figure 9. Zenith duct errors at the simulated location $\left(120.3^{\circ} \mathrm{E}, 39.9^{\circ} \mathrm{N}\right)$.

\subsection{Non-Nominal Troposphere}

An analysis of the ECMWF data indicates that the duct and non-nominal troposphere anomalies can occur simultaneously. Figure 10 shows the temperature, pressure, and specific humidity conditions for location $\left(50.7^{\circ} \mathrm{N}, 75.6^{\circ} \mathrm{E}\right)$ on 11 June 2016. The troposphere meteorological parameters fluctuate remarkably from 11:00 to 12:00, which is indicative of the non-nominal troposphere. Figure 11 shows the duct anomaly observed at 12:00 on that day. In addition, Table 1 shows the meteorological conditions and refractivity gradients at a location $\left(120.3^{\circ} \mathrm{E}, 39.9^{\circ} \mathrm{N}\right)$ in the Bohai Sea when the change in temperature exceeds $5^{\circ} \mathrm{C} / \mathrm{h}$. There are 7 samples of 10 for which the absolute refractivity gradient exceeds $100 / \mathrm{km}$.

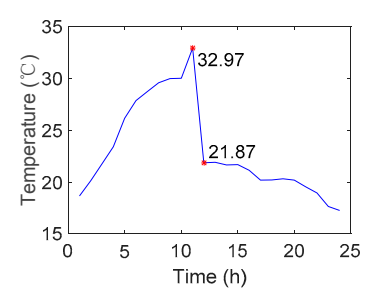

(a)

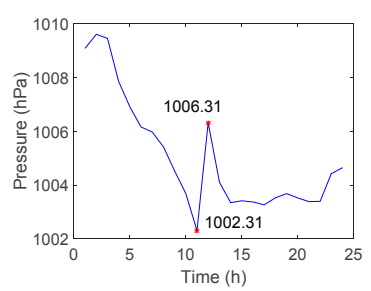

(b)

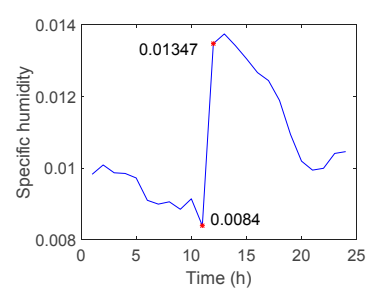

(c)

Figure 10. Temperature (a); pressure (b); and specific humidity (c) conditions for location $\left(50.7^{\circ} \mathrm{N}\right.$, $75.6^{\circ} \mathrm{E}$ ) on 11 June 2016.

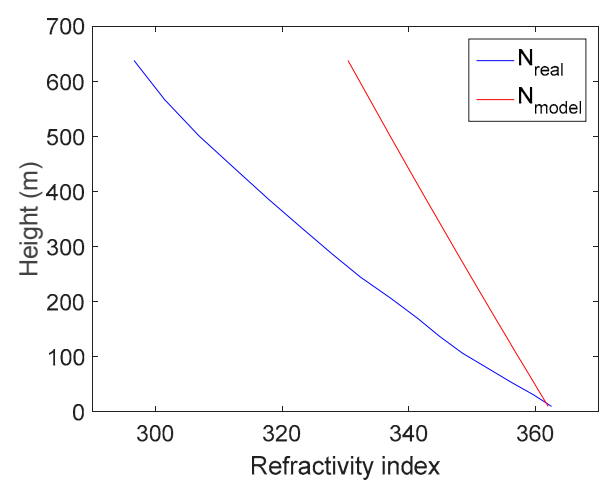

Figure 11. Duct anomaly observed at 12:00 for location $\left(50.7^{\circ} \mathrm{N}, 75.6^{\circ} \mathrm{E}\right)$ on 11 June 2016. 
Table 1. Meteorological conditions and refractivity gradients at location $\left(120.3^{\circ} \mathrm{E}, 39.9^{\circ} \mathrm{N}\right)$.

\begin{tabular}{ccccc}
\hline Time & $\begin{array}{c}\text { Temperature } \\
\text { Change }\left({ }^{\circ} \mathbf{C} / \mathbf{h}\right)\end{array}$ & $\begin{array}{c}\text { Pressure } \\
\text { Change } \\
\mathbf{( h P a / h )}\end{array}$ & $\begin{array}{c}\text { Specific } \\
\text { Humidity } \\
\text { Change }(/ \mathbf{h})\end{array}$ & $\begin{array}{c}\text { Absolute } \\
\text { Refractivity } \\
\text { Gradient (/km) }\end{array}$ \\
\hline 31 July 2010 05:00 & 6.4928 & 1.461 & 0.0050 & 117.56 \\
14 April 2011 19:00 & 5.8820 & 1.4481 & 0.0016 & 89.124 \\
17 March 2013 20:00 & 11.057 & 3.68 & 0.0027 & 63.027 \\
4 August 2013 17:00 & 5.0482 & 1.9732 & 0.0029 & 103.06 \\
23 September 2013 03:00 & 5.2567 & 1.3430 & 0.0036 & 114.7 \\
25 October 2014 18:00 & 5.0274 & 1.8183 & 0.0023 & 123.31 \\
21 March 2015 17:00 & 6.9922 & 2.6325 & 0.0013 & 186.97 \\
15 April 2015 14:00 & 5.6072 & 1.5774 & 0.00095 & 120.00 \\
16 February 2017 00:00 & 5.5364 & 1.9954 & 0.0013 & 86.49 \\
11 March 2017 15:00 & 5.0696 & 1.4906 & 0.000637 & 140.6 \\
31 July 2010 05:00 & 6.4928 & 1.461 & 0.0050 & 117.56 \\
14 April 2011 19:00 & 5.8820 & 1.4481 & 0.0016 & 89.124 \\
\hline
\end{tabular}

The non-nominal tropospheric error calculation process is as follows:

1. Calculate the maximum hourly changes in temperature, pressure, and specific humidity.

2. Use the above values to establish the Weather Wall parameters.

3. Calculate the bounds on the tropospheric delay difference between the ship and aircraft using the Weather Wall model and the Modified Hopfield model [2], which are non-nominal tropospheric errors.

The maximum hourly changes of temperature, pressure, and specific humidity in the Bohai Sea and Yellow Sea from 2010 to 2017 are calculated based on ECMWF data to be $12.77^{\circ} \mathrm{C} / \mathrm{h}, 13.21 \mathrm{hPa} / \mathrm{h}$ and $0.0078 / \mathrm{h}$, respectively. Since the input parameter of the modified Hopfield model is the relative humidity, the specific humidity change is converted to a relative humidity change, being approximately $48 \%$ [2,15].

Based on the above meteorological data analysis, the troposphere weather parameters are as follows:

1. Nominal weather conditions: $\mathrm{T}_{\mathrm{w}}=33^{\circ} \mathrm{C}, \mathrm{P}_{\mathrm{w}}=990 \mathrm{hPa}, \mathrm{RH}_{\mathrm{w}}=50 \%$. The temperature lapse rate is set to $-6.5 \mathrm{~K} / \mathrm{km}$.

2. Weather wall conditions: $\mathrm{T}_{0}=20^{\circ} \mathrm{C}, \mathrm{P}_{0}=1004 \mathrm{hPa}, \mathrm{RH}_{0}=100 \%$. The temperature lapse rate is set to $-6.5 \mathrm{~K} / \mathrm{km}$.

The non-nominal tropospheric errors are related to the satellite elevation and the horizontal distance between the aircraft and the ship station.

The horizontal distance between the aircraft and the ship station is the sum of the distance from the aircraft to the runway threshold and the distance from the landing threshold point to the ship station in the worst case. For GBAS, the landing threshold point is approximately $5 \mathrm{~km}$ or $10 \mathrm{~km}$ from the GBAS reference station [20]. However, in Sea-Based JPALS, the ship deck area is limited. The lengths of the United States Gerald R. Ford class aircraft carrier, the United States Nimitz class nuclear-powered aircraft carrier, and the Chinese "Liaoning" aircraft carrier are approximately $335 \mathrm{~m}$, $332.85 \mathrm{~m}$, and $304.5 \mathrm{~m}$, respectively [21-23], so the distance from the landing threshold point to the ship station is assumed to be $300 \mathrm{~m}$. In addition, the approach of the aircraft from a height of approximately $500 \mathrm{~m}$ from the landing point and a horizontal distance of approximately $17.7 \mathrm{~km}$ is considered.

Therefore, the non-nominal tropospheric error when the horizontal distance between the aircraft and the ship station is approximately $18 \mathrm{~km}$ is calculated and then fitted to an exponential function of the satellite elevation $\theta$, as shown in Figure 12. 


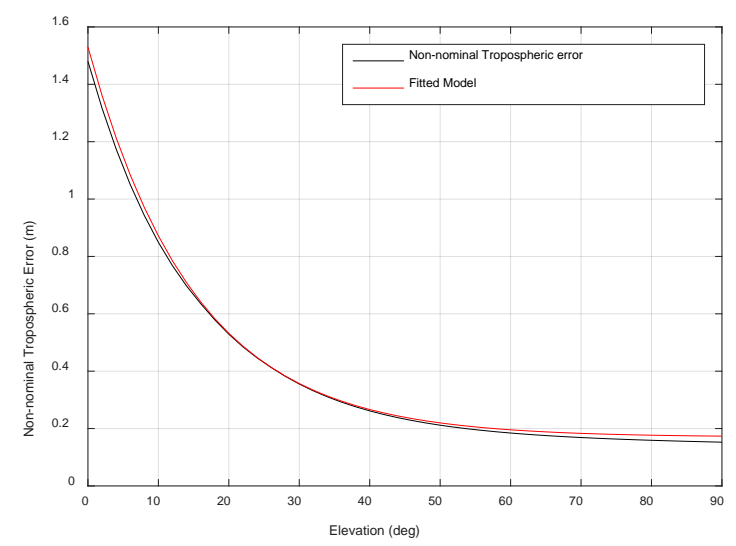

Figure 12. Non-nominal tropospheric error and fitted model.

The black line in Figure 12 represents the non-nominal tropospheric errors at different elevation ranges, while the red line represents the fitted model as the following equation.

$$
\mu=1.36 \times \exp \left(-\frac{\theta}{15.11}\right)+0.17
$$

The three constants in the model can be broadcast by the ship to the aircraft as integrity parameters. Then, the fitted model can be constructed on the aircraft and used to estimate the bound value of the non-nominal error for the satellites affected by the Weather Wall.

The satellites whose signals pass through the Weather Wall will be affected by the non-nominal troposphere. To select the affected satellite subset $Q$, the azimuth of the wall needs to be determined. As the Weather Wall exists at one side of the aircraft and the specific azimuth of the wall is not certain, we search for the azimuth of the wall in steps of $10^{\circ}$, as shown in Figure 13, considering the worst satellite geometry possible. The azimuth is selected where the value of $\sum_{Q} S_{\text {vert }} \times \mu$ is maximal in each epoch [10]. $S_{\text {vert }}$ is the vertical component of the geometry matrix for the visible satellite [24]. $\mu$ is the bound value of the non-nominal tropospheric error calculated using the fitted model.

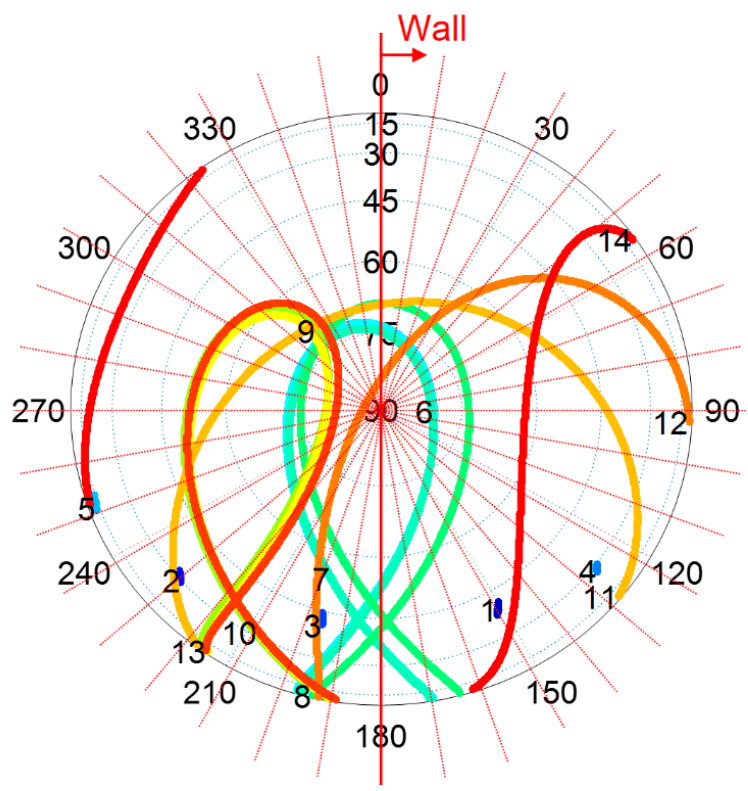

Figure 13. Searching for the azimuth of the Weather Wall in steps of $10^{\circ}$. The skyplot of the simulated location over the simulated day is for BeiDou Navigation Satellite System (BDS). 


\section{VPL under Tropospheric Anomalies}

The errors caused by tropospheric anomalies are non-zero mean errors. The errors will decrease as the distance between the aircraft and the ship decreases. However, when the distance between the aircraft and the ship is not small enough, the errors cannot be eliminated during the differential correction process. Therefore, the error sources should be bounded in integrity monitoring.

The VPL is an important indicator for assessing the Sea-Based JPALS performance. The VPL provides a confidence boundary to bound the positioning error with a large probability (defined by an integrity risk of less than $10^{-7}$ ) [9].

The protection level calculation methods under tropospheric anomaly hypothesis proposed previously are based on the least squares method. However, because of the highly stringent requirements for sea-based applications, Sea-Based JPALS is generally based on carrier-phase differential positioning and Kalman filtering [9]. Therefore, a protection level calculation method under the tropospheric anomaly hypothesis based on Kalman filtering is proposed.

In 2004, Frank Van Graas proposed an alternate VPL methodology that bounds the zero mean error and non-zero mean bias error separately [25]. This VPL consists of the component $V P L_{\text {non }}$ bounding zero mean errors and the component $V P L_{\text {bias }}$ bounding bias errors.

$$
V P L=V P L_{\text {non }}+V P L_{\text {bias }}
$$

\subsection{VPL non Calculation}

The nominal errors under the fault-free hypothesis (H0) are assumed to follow a zero-mean Gaussian distribution and are bounded by the component $V P L_{n o n}$. The ship subsystem receiver failures are protected by additional protection levels, which are not considered in this paper.

For Sea-Based JPALS, Samer Khanafseh and Boris Pervan proposed two types of positioning methods based on a Kalman filter: the averaging approach and the coupled estimation approach [13]. The coupled estimation approach was found to provide better performance than the averaging method. Therefore, the $V P L_{\mathrm{H} 0}$ calculation method for the coupled estimation approach is used to calculate $V P L_{\text {non }}$.

For the fault-free missed detection multiplier $K_{\text {ffmd }}$, the method in Ref. [13] does not consider the incorrect fix risk of the integer ambiguity in carrier-phase measurements. Therefore, the multiplier $K_{\text {ffmd }}$ is recalculated considering the probability of incorrect fix $\left(P_{\mathrm{IF}}\right)$ of the integer ambiguity [26].

When the allocated integrity risk is $10^{-7}, V P L_{\text {non }}$ is defined by

$$
\operatorname{Prob}\left\{\left|\hat{x}_{\text {vert }}-x_{\text {vert }}\right|>V P L_{\text {non }} \mid C F\right\} \cdot\left(1-P_{\mathrm{IF}}\right)+\operatorname{Prob}\left\{\left|\hat{x}_{\text {vert }}-x_{\text {vert }}\right|>V P L_{\text {non }} \mid I F\right\} \cdot P_{\mathrm{IF}}=10^{-7}
$$

where $x_{\text {vert }}$ is the true value of the vertical positioning component $\hat{x}_{\text {vert }}, \mathrm{CF}$ indicates that the integer ambiguity is fixed correctly, and IF indicates an incorrect fix.

Given an incorrect fix, it is assumed that the resulting position error will generally be large. Therefore, we obtain

$$
\begin{gathered}
\operatorname{Prob}\left\{\left|\hat{x}_{\text {vert }}-x_{\text {vert }}\right|>V P L_{\text {non }} \mid I F\right\} \approx 1 \\
\operatorname{Prob}\left\{\left|\hat{x}_{\text {vert }}-x_{\text {vert }}\right|>V P L_{\text {non }} \mid C F\right\}=\frac{10^{-7}-P_{\mathrm{IF}}}{1-P_{\mathrm{IF}}}
\end{gathered}
$$

so that $V P L_{\mathrm{H} 0}$ is

$$
V P L_{\text {non }}=K_{\text {ffmd }}\left(P_{\mathrm{IF}}\right) \cdot \sigma_{\text {vert } \mid C F}
$$

where $\sigma_{\text {vert } \mid \mathrm{CF}}$ is the vertical position error standard deviation obtained from the variance-covariance matrix of the relative positioning solution based on the Kalman filter. If $P_{\mathrm{IF}}$ is assumed to be less than $10^{-8}$, then $K_{\text {ffmd }}$ is approximately 5.35 . 


\subsection{VPL bias Calculation}

The non-zero mean vertical positioning bias errors caused by tropospheric anomalies are bounded by $V P L_{\text {bias }}$.

For the duct anomaly, the worst-case zenith duct error is used as a bound value $\gamma$ for all zenith duct errors $d$.

$$
|d| \leq \gamma
$$

Multiplying the zenith error $\gamma$ by the vector a of the obliquity factors for visible satellites results in the duct error vector $\mu_{\text {duct }}$ in the measurement domain.

$$
\mu_{\text {duct }}=\mathbf{a} \gamma
$$

For the non-nominal troposphere, the non-nominal tropospheric errors are calculated using the fitted exponential model in the section above. Then, the vector $\mu_{\text {non-nominal }}$ of non-nominal tropospheric errors for visible satellites is obtained. Note that the errors of the satellites not impacted by the Weather Wall are zero.

If the duct and non-nominal troposphere anomalies are simultaneously taken into account, then the total tropospheric error vector $\mu_{\text {tropo }}$ is

$$
\mu_{\text {tropo }}=\mu_{\text {non-nominal }}+\mu_{\text {duct }}
$$

In Sea-Based JPALS, the relative positions of the ship and the aircraft are calculated based on the Kalman filter. For the tropospheric delay on path 1, the TC model is used to correct the ship measurements. Then, the measurements of the ship and the aircraft are double differenced [17]. Since $\mu_{\text {tropo }}$ is the residual tropospheric error in single differenced measurements between the ship and aircraft, the residual tropospheric error $\Delta \mu_{\text {tropo }}$ in double-differenced measurements is the difference between the residual tropospheric errors $\mu_{\text {tropo }}$ of different satellites.

$$
\Delta \boldsymbol{\mu}_{\text {tropo }}=\left[\begin{array}{c}
\boldsymbol{\mu}_{\text {tropo }}^{1}-\boldsymbol{\mu}_{\text {tropo }}^{m} \\
\vdots \\
\boldsymbol{\mu}_{\text {tropo }}^{m-1}-\boldsymbol{\mu}_{\text {tropo }}^{m} \\
\boldsymbol{\mu}_{\text {tropo }}^{m+1}-\boldsymbol{\mu}_{\text {tropo }}^{m} \\
\vdots \\
\boldsymbol{\mu}_{\text {tropo }}^{n}-\boldsymbol{\mu}_{\text {tropo }}^{m}
\end{array}\right]
$$

where $n$ is the number of available satellites. $m$ represents the reference satellite, which generally has the highest elevation.

Based on the standard equation for updating the state vector $\delta \hat{\mathbf{x}}$ in a Kalman filter, the positioning bias error caused by the tropospheric anomalies is estimated as follows:

$$
\delta \hat{\mathbf{x}}(k \mid k)=\delta \hat{\mathbf{x}}(k \mid k-1)+\mathbf{K}(k)\left(\Delta \boldsymbol{\mu}_{\text {tropo }}(k)-\mathbf{H}(k) \cdot \delta \hat{\mathbf{x}}(k \mid k-1)\right)
$$

where $\mathbf{K}(k)$ is the Kalman filter gain matrix of the $k$-th state and $\mathbf{H}(k)$ is the measurement matrix of the $k$-th state.

By extracting the element that corresponds to the vertical component $\delta \hat{x}_{v}$ from $\delta \hat{\mathbf{x}}, V P L_{\text {bias }}$ under the duct hypothesis is computed as

$$
V P L_{\text {bias }}=\delta \hat{x}_{v}
$$

Then, the VPL under the duct hypothesis is computed as

$$
V P L=\delta \hat{x}_{v}+K_{\mathrm{ffmd}}\left(P_{\mathrm{IF}}\right) \cdot \sigma_{\mathrm{vert} \mid \mathrm{CF}}
$$




\section{Simulations}

\subsection{Simulation Options and Parameters}

In this work, a straight-in approach (Case-III landing approach) is assumed [26,27]. The simulation area begins with the aircraft being $500 \mathrm{~m}$ above the ship and the horizontal distance being approximately $17.70 \mathrm{~km}$, as shown in Figure 14 .

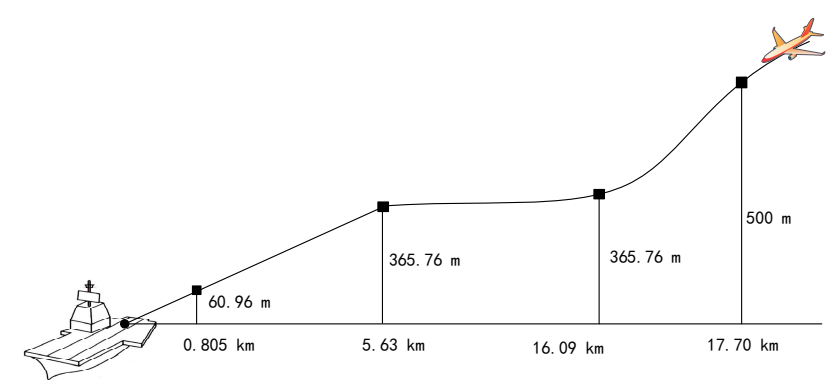

Figure 14. Simulation area of aircraft landing.

A given approach is said to be available if the integrity requirements are satisfied at each point along the approach. In this paper, the vertical alert limit (VAL) for Sea-Based JPALS is set to be $1.8 \mathrm{~m}$ according to reference [11].

To account for the GNSS satellite geometry change, the simulation duration is one day, and the interval is $10 \mathrm{~s}$.

For the duct anomaly, the zenith error is set to be $45.64 \mathrm{~mm}$ at a $500 \mathrm{~m}$ height and decreases linearly with the height during the approach. For the non-nominal troposphere, the error decreases linearly with the horizontal distance between the aircraft and the ship.

The parameters of the TC uncertainty are obtained by calculating the annual mean value and standard deviation of the data at the simulated location in 2017. The tropospheric scale height is $7583.9 \mathrm{~m}$, the refractivity index is 328.6 , and the refractivity index uncertainty is 29.5 .

Simulation options:

1. Location: $120.3^{\circ} \mathrm{E}, 39.9^{\circ} \mathrm{N}$.

2. Integrity risk: $10^{-7}[9]$.

3. Constellations: current GPS constellation and current BDS constellation.

4. Multipath and receiver noise error model: both code and carrier errors were modeled as first-order Gauss-Markov measurement error models. The time constants in the model for the ship and aircraft are $60 \mathrm{~s}$ and $30 \mathrm{~s}$, respectively [11,28].

5. Standard deviation of pseudorange measurement error: $0.35 \mathrm{~m}$.

6. Standard deviation of carrier-phase measurement error: $0.007 \mathrm{~m}$.

7. Mask angle: $7.5^{\circ}$ (accounting for potential obstructions in the shipboard environment and loss of low-elevation lines of sight at the aircraft due to attitude motion [26]).

\subsection{Results Analysis}

Figure 15 shows the VPL simulation results based on the above options.

$V P L_{\text {normal }}$ is the VPL under the fault-free hypothesis.

$V P L_{\text {duct }}$ is the VPL when only the duct anomaly is considered.

$V P L_{\text {non }}$ is the VPL when only the non-nominal troposphere is considered.

$V P L_{\text {duct,non }}$ is the VPL when both the duct anomaly and the non-nominal troposphere are considered. 


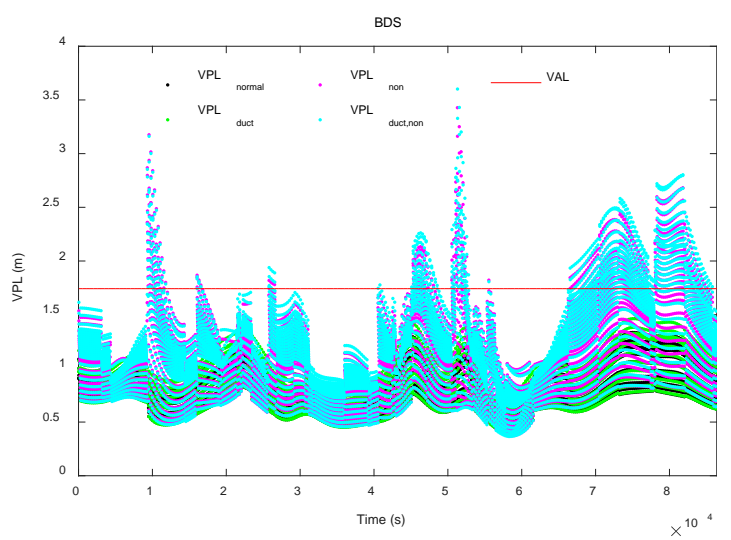

(a) BDS

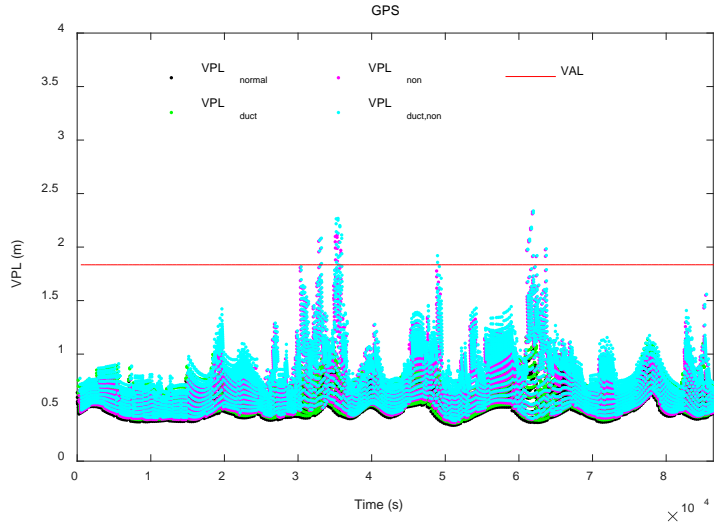

(b) GPS

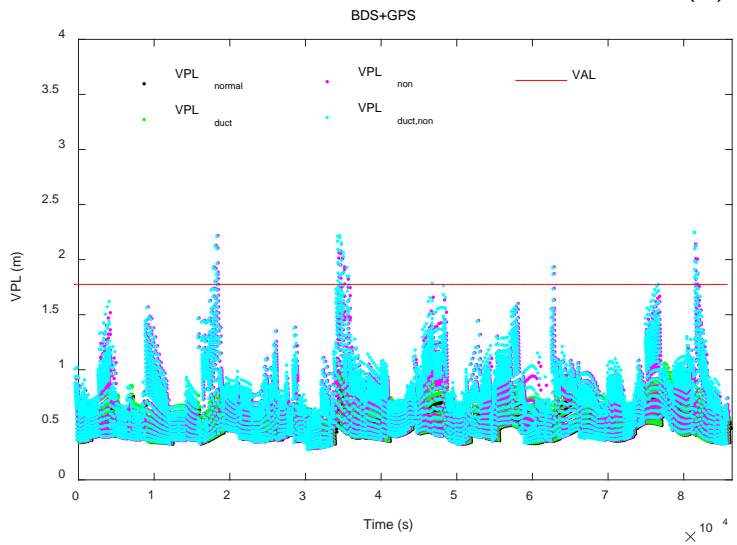

(c) BDS + GPS

Figure 15. Vertical Protection Level (VPL) simulation results under BDS/Global Positioning System (GPS)/BDS + GPS constellations.

According to Table 2, the average VPL increment caused by only the duct anomaly is $0.082 \mathrm{~m}$ with a growth percentage of $12.903 \%$; the average VPL increment caused by only the non-nominal troposphere is $0.211 \mathrm{~m}$ with a growth percentage of $30.857 \%$. The average VPL increment caused by the two tropospheric anomalies is $0.272 \mathrm{~m}$ with a growth percentage of $40.427 \%$.

Table 2. Average VPL increments and growth percentages under tropospheric anomalies.

\begin{tabular}{cccc}
\hline VPL Increments (m)/Percentage & BDS & GPS & BDS + GPS \\
\hline Duct anomaly & $0.085 / 9.98 \%$ & $0.083 / 14.23 \%$ & $0.079 / 14.50 \%$ \\
Non-nominal troposphere & $0.332 / 38.90 \%$ & $0.127 / 21.77 \%$ & $0.173 / 31.90 \%$ \\
Both anomalies & $0.398 / 46.57 \%$ & $0.188 / 32.39 \%$ & $0.230 / 42.32 \%$ \\
\hline
\end{tabular}

Figure 15 and Table 2 indicate that the following inequality can be obtained:

$$
V P L_{\text {duct,non }}>V P L_{\text {non }}>V P L_{\text {duct }}>V P L_{\text {normal }}
$$

The inequality indicates that the introduction of non-nominal tropospheric and duct anomaly errors increases VPL and that the impact of non-nominal tropospheric errors is greater than that of duct anomaly errors.

For availability, if the protection level exceeds the alarm limit at some point during the approach, the approach is considered unavailable. The typical availability requirement for Sea-Based JPALS specified in references $[9,26]$ is $99.7 \%$. To calculate the average availability, the simulation time is extended to 10 days. The results are shown in Table 3. Under the fault-free hypothesis, the average 
availability is $100 \%$. When the duct anomaly and non-nominal troposphere are considered separately, the average availabilities are $99.983 \%$ and $96.326 \%$, respectively. Although the loss of availability is small when only the duct anomaly is considered, when the two tropospheric anomalies are considered simultaneously, the average availability is $95.257 \%$, with a loss of $4.743 \%$ relative to fault-free availability.

Table 3. Average availability results under tropospheric anomalies for 10 days (86,400 epochs).

\begin{tabular}{cccc}
\hline $\begin{array}{c}\text { Number of Unavailable } \\
\text { Epochs/Average Availability }\end{array}$ & BDS & GPS & BDS + GPS \\
\hline $\begin{array}{c}\text { Nominal } \\
\text { Duct anomaly }\end{array}$ & $0 / 100 \%$ & $0 / 100 \%$ & $0 / 100 \%$ \\
Non-nominal troposphere & $83 / 99.950 \%$ & $0 / 100 \%$ & $0 / 100 \%$ \\
Both anomalies & $11250 / 86.979 \%$ & $476 / 99.449 \%$ & $567 / 99.344 \%$ \\
\hline
\end{tabular}

From Tables 2 and 3, it is found that the impact of tropospheric anomalies under the BDS constellation is greater than that under the GPS constellation. There may be two main reasons. First, for the simulated location, the elevations of the five BDS GEO satellites are all below $45^{\circ}$, and thus the duct errors of the GEO satellites are relatively large. Second, during the simulation, the percent of the epochs when the five BDS GEO satellites (PRN 1 to PRN 5) are affected by the non-nominal troposphere are $98.83 \%, 98.69 \%, 100 \%, 90.39 \%$, and $85.20 \%$, respectively. The likelihood that the five satellites are all affected is $75.59 \%$. And the non-nominal tropospheric errors of these GEO satellites are large due to the low elevations.

\section{Conclusions}

An analysis based on the published 8-year historical meteorological data of China and the surrounding areas from ECMWF shows that the duct anomaly and non-nominal troposphere can occur simultaneously.

For the duct anomaly, the maximum zenith error is observed to be $45.64 \mathrm{~mm}$, and the duct error has a prominent seasonal characteristic in that the errors in the summer are generally larger than those in the other three seasons. For the non-nominal troposphere, the worst meteorological conditions in China's surrounding sea areas are used to calculate non-nominal errors, and then a satellite-elevation-dependent fitting model is obtained. Finally, a protection level calculation method based on Kalman filtering under tropospheric anomalies is proposed, and the simulation of multiple landing approaches is conducted.

The results show that the average VPL increments introduced by the duct and non-nominal troposphere anomalies are $0.082 \mathrm{~m}$ and $0.211 \mathrm{~m}$, respectively; the growth percentages are $12.903 \%$ and $30.857 \%$, respectively. The average VPL increments under simultaneous anomalies is $0.272 \mathrm{~m}$ with a growth of $40.427 \%$. Tropospheric anomaly hypotheses cause some loss of system availability. The average availability of the system under normal conditions is $100 \%$. For the duct anomaly and the non-nominal troposphere the availability loss is $0.017 \%$ and $3.674 \%$, respectively. Under simultaneous anomalies, the availability loss is $4.743 \%$. The simultaneous occurrence of tropospheric anomalies is expected to adversely affect the Sea-Based JPALS integrity and availability.

The above results are somewhat conservative, mainly in regard to two aspects. First, the maximum zenith duct error obtained based on the 8-year meteorological data of China and the surrounding areas is used in the simulation. In practical applications, different error bound values can be set according to the specific season and location. Second, the azimuth of the Weather Wall in the simulation is selected considering the worst satellite geometry possible. The detection method of this azimuth needs further study.

The protection level calculation method proposed in this paper can bound the errors caused by tropospheric anomalies, but this method requires the modification of the airborne integrity architecture. 
In future work, we plan to develop a method accounting for tropospheric anomalies without modifying the airborne architecture in Sea-Based JPALS.

Author Contributions: Y.Z. and Z.W. conceived of and designed the research. Y.Z. performed the experiments, analyzed the results and wrote the paper. Y.Z. and Z.W. were responsible for data acquisitions, data processing and project managing. All authors participated in the project and approved the final manuscript.

Funding: The work was carried out with financial support under the National Natural Science Foundation of China (Grant No. 61501010, U1433114), the Aeronautics Science Foundation (Grant No. 2015ZC51035), and a major project on the second satellite navigation system of China (Grant No. GFZX0305030106).

Acknowledgments: The authors thank the staff of the National Key Laboratory of CNS/ATM for their advice and interest.

Conflicts of Interest: The authors declare no conflict of interest.

\section{References}

1. Kaplan, E.D.; Hegarty, C.J. Understanding GPS: Principles and Applications, 2nd ed.; Kou, Y.H., Translator; Publishing House of Electronics Industry: Beijing, China, 2012; pp. 181-222.

2. Xu, G.; Xu, Y. GPS: Theory, Algorithms and Applications, 3rd ed.; Springer: New York, NY, USA, 2016; pp. 80-90.

3. Mcgraw, G.A. Tropospheric error modeling for high integrity airborne GNSS navigation. In Proceedings of the 2012 IEEE/ION Position, Location and Navigation Symposium, Myrtle Beach, SC, USA, 23-26 April 2012; pp. 158-166.

4. Huang, J.; Graas, F.V.; Cohenour, C. Characterization of tropospheric spatial decorrelation errors over a 5-km Baseline. Navigation 2008, 55, 39-53. [CrossRef]

5. Ken, F.; Mcdonald, J.; Johnson, B. Observed nominal atmospheric behavior using honeywell's GAST D Ionosphere gradient monitor. In Proceedings of the CSG Meeting, Montreal, MB, Canada, 17-20 May 2014.

6. Guilbert, A.; Milner, C.; Macabiau, C. Characterization of tropospheric gradients for the ground-based augmentation system through the use of numerical weather models. Navigation 2017, 64, 475-493. [CrossRef]

7. Offer, C.R.; Groves, P.D.; Macaulay, A.A.; Nash, D.L.J; Mather, C.J. Use of inertial integration to enhance availability for shipboard relative GPS (SRGPS). In Proceedings of the 19th International Technical Meeting of the Satellite Division of the Institute-of-Navigation, Ft Worth, TX, USA, 26-29 September 2006; pp. 726-737.

8. Gold, K.L.; Brown, A.K. A hybrid integrity solution for precision landing and guidance. In Proceedings of the Position Location and Navigation Symposium, Monterey, CA, USA, 26-29 April 2004; pp. 165-174.

9. Rife, J.; Khanafseh, S.; Pullen, S. Navigation, interference suppression, and fault monitoring in the sea-based joint precision approach and landing system. Proc. IEEE 2009, 96, 1958-1975. [CrossRef]

10. Guilbert, A. Non-nominal troposphere reassessment for meeting CAT II/III with MC/MF GBAS. In Proceedings of the 28th International Technical Meeting of the Satellite Division of the Institute of Navigation (ION GNSS + 2015), Tampa, FL, USA, 14-18 September 2015; pp. 1526-1537.

11. Khanafseh, S.; Joerger, M.; Pervan, B.; Engeln, A.V. Accounting for tropospheric anomalies in high integrity and high accuracy positioning applications. In Proceedings of the 24th International Technical Meeting of the Satellite Division of the Institute of Navigation (ION GNSS 2011), Portland, OR, USA, 20-23 September 2011; pp. 513-522.

12. Wang, Z.; Xin, P.; Li, R. A method to reduce non-nominal troposphere error. Sensors 2017, 17, 1751. [CrossRef] [PubMed]

13. Khanafseh, S.; Pervan, B. Detection and mitigation of reference receiver faults in differential carrier phase navigation systems. IEEE Trans. Aerosp. Electron. Syst. 2011, 47, 2391-2404. [CrossRef]

14. Mather, C.; Macaulay, A.; Mole, S. Performance of integrity monitoring techniques for shipboard relative GPS landing systems. In Proceedings of the International Technical Meeting of the Satellite Division of the Institute of Navigation, Long Beach, CA, USA, 13-16 September 2005; pp. 2882-2894.

15. Chen, Q.; Song, S.; Heise, S. Assessment of ZTD derived from ECMWF/NCEP data with GPS ZTD over China. GPS Solut. 2011, 15, 415-425. [CrossRef]

16. Khanafseh, S.; Engeln, A.V.; Pervan, B. Tropospheric duct anomaly threat model for high integrity and high accuracy navigation. In Proceedings of the 29th International Technical Meeting of the Satellite Division of the Institute of Navigation (ION GNSS + 2016), Portland, OR, USA, 12-16 September 2016; pp. 1609-1616. 
17. Dogra, S.; Wright, J.; Hansen, J. Sea-based JPALS relative navigation algorithm development. In Proceedings of the ION GNSS 18th International Technical Meeting of the Satellite Division, Long Beach, CA, USA, 13-16 September 2005; pp. 2871-2881.

18. Mcgraw, G. Development of the LAAS accuracy models. In Proceedings of the 13th International Technical Meeting of the Satellite Division of the Institute of Navigation, Salt Lake City, UT, USA, 19-22 September 2000; pp. 1212-1223.

19. Li, W.; Yuan, Y.B.; Ou, J.K. A new global zenith tropospheric delay model IGGtrop for GNSS applications. Sci. Bull. 2012, 57, 2132-2139. [CrossRef]

20. NSP Working Group. GBAS CAT II/III Development Baseline SARPs; International Civil Aviation Organization: Montreal, QC, Canada, 2010.

21. NAVAL Technology. Gerald R Ford Class (CVN 78/79)—US Navy CVN 21 Future Carrier Programme. Available online: https:/ / www.naval-technology.com/projects/cvn-21/ (accessed on 30 April 2018).

22. FAS. CVN-68 Nimitz-Class. Available online: https://fas.org/man/dod-101/sys/ship/cvn-68.htm (accessed on 30 April 2018).

23. Hai, Y. The "Liaoning" Aircraft Carrier. Available online: http:// ocean.china.com.cn/2013-01/06/content_ 27600953.htm (accessed on 30 April 2018).

24. RTCA DO-253C. Minimum Operational Performance Standards for GPS Local Area Augmentation System Airborne Equipment; RTCA: Washington, DC, USA, 2008.

25. Van Graas, F.; Krishnan, V.; Suddapalli, R.; Skidmore, T. Conspiring biases in the local area augmentation system. In Proceedings of the ION 60th Annual Meeting/US Air Force Institute of Technology \& the US Air force Research Laboratory, Dayton, OH, USA, 7-9 June 2004; The Institute of Navigation: Manassas, VA, USA, 2004; pp. 300-307.

26. Pervan, B.; Chan, F.; Gebre-Egziabher, D. Performance analysis of carrier-phase DGPS navigation for shipboard landing of aircraft. Navigation 2003, 50, 181-191. [CrossRef]

27. Langel, S.E.; Khanafseh, S.M.; Chan, F.C. Cycle ambiguity reacquisition in UAV applications using a novel GPS/INS integration algorithm. In Proceedings of the Institute of Navigation National Technical Meeting, Anaheim, CA, USA, 26-28 January 2009; Volume 5538, pp. 1026-1037.

28. O'Keefe, K.; Petovello, M.; Lachapelle, G.; Cannon, M.E. Assessing probability of correct ambiguity resolution in the presence of time-correlated errors. Navigation 2006, 53, 269-282. [CrossRef] 